\title{
Associations between schizotypy and belief in conspiracist ideation
}

\author{
David Barron ${ }^{a, *}$, Kevin Morgan ${ }^{a}$, Tony Towell a , Boris Altemeyer ${ }^{a}$, Viren Swami ${ }^{a, b}$ \\ ${ }^{a}$ Department of Psychology, University of Westminster, London, UK \\ ${ }^{\mathrm{b}}$ Department of Psychology, HELP University College, Kuala Lumpur, Malaysia
}

\section{A R T I C L E I N F O}

Article history:

Received 18 February 2014

Accepted 25 June 2014

\section{Keywords}

Conspiracy theories

Conspiracist ideation

Schizotypy

Odd Beliefs

Magical Thinking

Paranormal beliefs

\begin{abstract}
A B S T R A C T
Previous studies have reported associations between conspiracist ideation and domain-level facets of schizotypy, but less is known about associations with lower-order facets. In the present study, 447 adults completed measures of conspiracist ideation and the Schizotypal Personality Questionnaire (SPQ), consisting of nine subscales grouped into four domains. Results of a multiple regression showed that two domains of the SPQ significantly predicted conspiracist ideation, but multicollinearity was a limiting factor. In a second regression, we found that the subscales of Odd Beliefs or Magical Thinking and Ideas of Reference significantly predicted conspiracist ideation, without any multicollinearity constraints. We interpret these results as implicating two specific lower-order facets of schizotypy in belief in conspiracy theories. We further contrast the present results with previous studies indicating associations between conspiracist ideation and paranormal beliefs.
\end{abstract}

(c) 2014 Elsevier Ltd. All rights reserved.

\section{Introduction}

A conspiracy theory usually refers to a subset of false narratives in which the ultimate cause of an event is believed to be due to a malevolent plot by multiple actors working together (Swami \& Furnham, 2014). Studies have suggested that belief in conspiracy theories are widespread (e.g., Goertzel, 1994), which is of concern because they have the potential to sow civic discord and public mistrust (Swami \& Coles, 2010). In response, a new psychology of conspiracy theories has developed over the past several years, incorporating multiple perspectives spanning cognitive to differential psychology (for reviews, see Swami \& Coles, 2010; Swami \& Furnham, 2014).

A key focus of this work has been to problematise the traditional view that conspiracist ideation is the product of individual or collective psychopathology. Rather, conspiracy theories are now viewed as a subset of false beliefs that help individuals make sense of phenomena that are incomprehensible or beyond one's control (Swami \& Furnham, 2014); that is, they are rational attempts to deal with the psychological feelings triggered by complex phenomena. Even so, this perspective does not rule out the possibility that conspiracist ideation, measured as a differential trait, will be associated with psychopathological indices, particu-

\footnotetext{
* Corresponding author. Address: Department of Psychology, University of Westminster, 309 Regent Street, London W1B 2UW, UK. Tel.: +44 2079115000.

E-mail address: david.barron@my.westminster.ac.uk (D. Barron).
}

larly those that point to underlying paranoia or delusional thinking (Swami et al., 2011).

In support of this perspective, researchers have recently begun examining associations between conspiracist ideation and traits such as paranoid ideation, superstitious beliefs, magical ideation, and belief in the paranormal (Brotherton, French, \& Pickering, 2013; Bruder, Haffke, Neave, Nouripanah, \& Imhoff, 2013; Darwin, Neave, \& Holmes, 2011; Stieger, Gumhalter, Tran, Voracek, \& Swami, 2013; Swami et al., 2011). In addition, three studies have reported significant associations between conspiracist ideation and schizotypal personality disposition (Bruder et al., 2013; Darwin et al., 2011; Swami et al., 2013). Schizotypy is believed to refer to one's proneness to schizophrenia and holds that there is a continuum of cognitive, perceptual, and affective characteristics and experiences ranging from normal dissociative states to extreme states (Claridge, 1997). In explanation, it has been suggested that the relationship is a function of schizotypal individuals being more open to arguments in support of conspiracy theories as a result of their suspiciousness of others (Darwin et al., 2011).

A potential constraint on this explanation, however, has been the limited way in which schizotypy has been measured in earlier studies. Thus, Swami et al. (2013) reported that scores on the Unusual Experiences subscale of the Oxford-Liverpool Inventory of Feelings and Experiences (O-LIFE; Mason, Claridge, \& Jackson, 1995) significant and positively predicted conspiracist ideation. Conversely, two other studies have reported significant associations between conspiracist ideation and three domains of 
schizotypy measured on the Schizotypal Personality Questionnaire-Brief (SPQ-B), namely Cognitive-Perceptual Deficit, Interpersonal Deficit, and Disorganisation; Bruder et al., 2013; Darwin et al., 2011). There are, however, questions concerning the reliability of the SPQ-B (Axelrod, Grilo, Sanislow, \& McGlashan, 2001), as well as the factorial validity of the three-factor model of schizotypy (Compton, Goulding, Bakeman, \& McClure-Tone, 2009). Moreover, use of domain-level dimensions may obscure associations between conspiracist ideation and lower-level schizotypal traits.

In the present study, we sought to extend the available literature by examining associations between conspiracist ideation and schizotypy, as measured by the full form of the SPQ consisting of nine subscales grouped into four domains. Doing so allowed us to examine associations between conspiracist ideation and domain schizotypy, as well as lower-level subscales of the SPQ. In terms of the latter, two prime candidates for associations with conspiracist ideation are (i) Paranoid Ideation/Suspiciousness, which would reflect the role of distrust of others, particularly those in authority, in conspiracist ideation (Darwin et al., 2011; Swami, ChamorroPremuzic, \& Furnham, 2010), and; (ii) Odd Beliefs or Magical Thinking, which would be consistent with previous reports of associations between conspiracist ideation and paranormal beliefs (Bruder et al., 2013; Darwin et al., 2011; Swami et al., 2011, 2013).

\section{Method}

\subsection{Participants}

The participants of this study were an online, international sample of 346 women and 101 men, who ranged in age from 18 to $68(M=23.17, S D=7.87)$. Most participants were from the United States of America (49.1\%) and the United Kingdom (36.4\%), with the remainder of the sample consisting of various nations (14.5\%). The sample consisted of $72 \%$ who had completed at least some college, with $98.4 \%$ completing high school.

\subsection{Measures}

\subsubsection{Conspiracist ideation}

The Belief in Conspiracy Theories Inventory (BCTI; Swami et al., 2010,2011 ) was used to measure general conspiracist ideation. The BCTI is a 15-item measure that describes a range of internationally-recognisable conspiracy theories, which are rated for agreement on a 9-point scale ( 1 = Completely false, $9=$ Completely true). An overall score is computed as the mean of all items and higher scores on this scale reflect greater conspiracist ideation. Previous work has shown that the scale is one-dimensional, has good internal consistency (Swami et al., 2010, 2011), and correlates very strongly with a non-event-based, generic measure of conspiracist ideation (Brotherton et al., 2013). In the present study, Cronbach's alpha for this scale was .92.

\subsubsection{Schizotypy}

We used the 74-item Schizotypal Personality Questionnaire (SPQ; Raine, 1991), which was designed to measure all nine diagnostic criteria for schizotypal personality disorder. Each 'yes' response counts as one point and nine subscale scores were computed as the total score for all items associated with each subscale. Table 1 shows Cronbach's alpha coefficients for the nine subscales in the present sample, which is in line with the findings of Compton et al. (2009). Scores for domains were derived by the summation of subscale scores. In the original development of the SPQ, Raine (1991) proposed a three-domain structure; more recently, however, Compton et al. (2009) reported that a fourdomain model had better fit indices. In the present study,
Table 1

Internal consistency reliabilities (Cronbach's $\alpha$ ) of the Schizotypal Personality Questionnaire subscales.

\begin{tabular}{lll}
\hline Subscale & Items & $\alpha$ \\
\hline Odd Beliefs or Magical Thinking $^{1}$ & 7 & .77 \\
Unusual Perceptual Experiences $^{1}$ & 9 & .74 \\
Ideas of Reference $^{2}$ & 9 & .80 \\
Paranoid Ideation/Suspiciousness $^{2 / 3}$ & 8 & .80 \\
Excessive Social Anxiety $^{2 / 3}$ & 8 & .81 \\
No Close Friends $^{3}$ & 9 & .80 \\
Constricted Affect $^{3}$ & 8 & .76 \\
Odd or Eccentric Behaviour $^{4}$ & 7 & .86 \\
Odd Speech $^{4}$ & 9 & .80
\end{tabular}

Note. Domain: ${ }^{1}$ Cognitive-perceptual, ${ }^{2}$ Paranoid, ${ }^{3}$ Negative, ${ }^{4}$ Disorganised (Stefanis et al., 2004).

therefore, we computed domain scores based on the four-domain model (see Table 1; Stefanis et al., 2004).

\subsubsection{Demographics}

Participants provided their demographic details consisting of age, sex, country of residence, education, and ethnicity.

\subsection{Procedure}

Ethics approval was obtained from the relevant university ethics committee.

The survey was launched in March 2012 and ran until January 2014. Survey dissemination was undertaken via multiple routes. On the one hand, the internal Research Participation Scheme at the University of Westminster was used. This scheme gives course credit to students who participate in research undertaken by members of staff. No monetary incentives were offered to the participants for completion of the survey. On the other hand, the survey was advertised at university-associated online platforms, primarily for institutions in the USA and UK. The participants gave a dual-consent; prior to and post-survey.

\section{Results}

Descriptive statistics for all variables included in the present study are reported in Table 2 . An independent-samples $t$-test showed that there was no significant difference in conspiracist ideation between women $(M=3.82, S D=1.60)$ and men $(M=3.83$, $S D=1.73), t(444)=0.05, p=.963, d<.01$, so the sample was combined for all further analyses. Inter-scale correlations between conspiracist ideation and the SPQ domains and subscales, respectively, are reported in Table 2. As can be seen, greater conspiracist ideation was significantly associated with higher scores on three SPQ domains (Cognitive-Perceptual, Paranoid, and Negative). In addition, greater conspiracist ideation was significantly associated with higher scores on six of the nine SPQ subscales.

To examine the predictive power of schizotypy, we computed two separate multiple linear regressions using the Enter method. In the first regression, we entered conspiracist ideation as the criterion variable and all SPQ domains as predictor variables. Results showed that the regression was significant, $F(4,446)=16.24$, $p<.001$, Adj. $R^{2}=.12$. As can be seen in Table 3, Cognitive-Perceptual and Disorganised emerged as significant predictors of conspiracist ideation, although multicollinearity was a limiting issue. In the second regression, we entered conspiracist ideation as the criterion variable and all SPQ subscales as predictor variables. The regression was again significant, $F(9,446)=8.75, p<.001$, Adj. $R^{2}=.14$. Regression coefficients are reported in Table 4 and, as can be seen, the only significant predictors of conspiracist ideation 
Table 2

Descriptive statistics and inter-scale correlations between conspiracist ideation and schizotypy.

\begin{tabular}{|c|c|c|c|c|c|c|c|c|c|c|c|c|c|c|c|}
\hline & (1) & $(2)$ & (3) & $(4)$ & $(5)$ & (6) & $(7)$ & $(8)$ & $(9)$ & $(10)$ & (11) & $(12)$ & $(13)$ & (14) & $(15)$ \\
\hline (1) Conspiracist ideation & & $.22^{* *}$ & $.32^{* * *}$ & $.23^{* *}$ & $.14^{*}$ & .09 & $.32^{* *}$ & $.25^{* *}$ & $.28^{* *}$ & $.24^{* *}$ & .03 & $.10^{*}$ & $.10^{*}$ & .08 & .08 \\
\hline (2) Total SPQ & & & $.79^{* * *}$ & $.91^{* *}$ & $.91^{* *}$ & $.84^{* *}$ & $.58^{* *}$ & $.79^{* *}$ & $.77^{* *}$ & $.81^{* *}$ & $.65^{* *}$ & $.74^{* *}$ & $.76^{* *}$ & $.72^{* *}$ & $.78^{* *}$ \\
\hline (3) CgP domain & & & & $.66^{* *}$ & $.55^{* *}$ & $.60^{* *}$ & $.86^{* *}$ & $.90^{* *}$ & $.67^{* *}$ & $.60^{* *}$ & $.35^{* *}$ & $.41^{* *}$ & $.42^{* *}$ & $.54^{* *}$ & $.55^{* *}$ \\
\hline (4) Pn domain & & & & & $.87^{* *}$ & $.62^{* *}$ & $.46^{* *}$ & $.67^{* *}$ & $.86^{* *}$ & $.87^{* *}$ & $.74^{* *}$ & $.60^{* *}$ & $.61^{* *}$ & $.50^{* *}$ & $.62^{* *}$ \\
\hline (5) Neg domain & & & & & & $.65^{* *}$ & $.37^{* *}$ & $.57^{* *}$ & $.59^{* *}$ & $.78^{* *}$ & $.78^{* * *}$ & $.86^{* *}$ & $.85^{* *}$ & $.53^{* *}$ & $.63^{* *}$ \\
\hline (6) Ds domain & & & & & & & $.39^{* *}$ & $.65^{* *}$ & $.55^{* *}$ & $.57^{* *}$ & $.43^{* * *}$ & $.53^{* *}$ & $.60^{* *}$ & $.89^{* *}$ & $.91^{* *}$ \\
\hline (7) OBMT & & & & & & & & $.53^{* *}$ & $.51^{* *}$ & $.41^{* *}$ & $.21^{* * *}$ & $.29^{* *}$ & $.29^{* *}$ & $.37^{* *}$ & $.34^{* *}$ \\
\hline (8) UPE & & & & & & & & & $.65^{* *}$ & $.62^{* *}$ & $.39^{* *}$ & $.42^{* *}$ & $.44^{* *}$ & $.56^{* *}$ & $.60^{* *}$ \\
\hline (9) IOR & & & & & & & & & & $.72^{* *}$ & $.39^{* * *}$ & $.39^{* *}$ & $.42^{* *}$ & $.45^{* *}$ & $.53^{* *}$ \\
\hline (10) PI & & & & & & & & & & & $.43^{* *}$ & $.55^{* *}$ & $.57^{* *}$ & $.48^{* *}$ & $.53^{* * *}$ \\
\hline (11) ESA & & & & & & & & & & & & $.54^{* *}$ & $.52^{* *}$ & $.32^{* *}$ & $.45^{* *}$ \\
\hline (12) NCF & & & & & & & & & & & & & $.73^{* *}$ & $.46^{* *}$ & $.48^{* *}$ \\
\hline (13) $\mathrm{CA}$ & & & & & & & & & & & & & & $.49^{* *}$ & $.58^{* *}$ \\
\hline (14) OEB & & & & & & & & & & & & & & & $.62^{* *}$ \\
\hline \multicolumn{16}{|l|}{ (15) OS } \\
\hline M & 3.81 & 24.09 & 3.99 & 9.68 & 11.24 & 5.72 & 1.53 & 2.46 & 3.13 & 2.68 & 3.87 & 2.60 & 2.09 & 2.30 & 3.42 \\
\hline SD & 1.63 & 15.48 & 3.54 & 6.20 & 7.67 & 4.43 & 1.87 & 2.18 & 2.65 & 2.36 & 2.54 & 2.47 & 2.04 & 2.35 & 2.56 \\
\hline
\end{tabular}

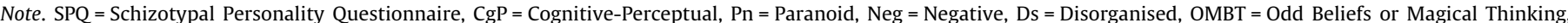

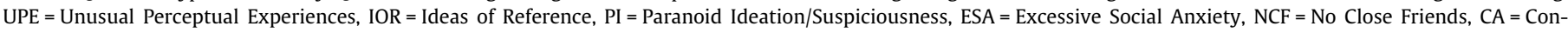
stricted Affect, OEB = Odd or Eccentric Beliefs, OS = Odd Speech.

${ }^{*} p<.01$.

** $p<.001$

Table 3

Regression coefficients for the regression predicting conspiracist ideation with SPQ domains entered as predictors.

\begin{tabular}{llllllll}
\hline & $B$ & $S E$ & $\beta$ & $t$ & $p$ & Tolerance & VIF \\
\hline Cognitive- & .17 & .03 & .36 & 5.74 & $<.001$ & .50 & 2.02 \\
$\quad$ Perceptual & & & & & & & \\
Paranoid & .05 & .03 & .19 & .189 & .060 & .20 & 4.91 \\
Negative & -.02 & .02 & -.10 & -1.02 & .307 & .23 & 4.40 \\
Disorganised & -.07 & .02 & -.18 & -2.90 & .004 & .49 & 2.03
\end{tabular}

were Odd Beliefs or Magical Thinking and Ideas of Reference. Multicollinearity was not a limiting issue in this regression.

\section{Discussion}

Our results support previous work (Bruder et al., 2013; Darwin et al., 2011; Swami et al., 2013) showing a robust association between conspiracist ideation and schizotypy. However, we believe that previous findings need to be interpreted with caution: previous studies have not considered multicollinearity between SPQ domains as a limiting factor. In our study, although we found that two SPQ domains significantly predicted conspiracist ideation, multicollinearity meant that conclusions about individual predictors should be treated with caution. Nevertheless, the general conclusion that schizotypy is associated with conspiracist ideation was supported in the present work.

When examining SPQ subscales, Odd Beliefs or Magical Thinking (OBMT) emerged as the strongest predictor of conspiracist ideation. This subscale and its parent domain have been shown to be associated with paranormal beliefs (e.g., Genovese, 2005; Hergovich, Schott, \& Arendasy, 2008), which in turn are associated with conspiracist ideation (Bruder et al. 2013;Darwin et al., 2011; Stieger et al., 2013; Swami et al., 2011). Swami et al. (2011) proposed that the latter association may reflect the fact that both conspiracist ideation and paranormal beliefs require a rejection of official mechanisms of information generation and expert opinion. That is, and consistent with the present results, it would seem that differential traits that lead an individual to hold unusual beliefs may also lead them to assimilate conspiracy theories.

What is to some extent unclear, however, is whether OBMT and paranormal beliefs are different concepts. Hergovich et al. (2008) showed that some aspects of paranormal beliefs (e.g., belief in precognition, psi, witchcraft, and spiritualism) were predicted very well by schizotypy, but other facts such as superstition were not. This would seem consistent with the finding that conspiracist ideation is associated with paranormal, but not superstitious, beliefs (Swami et al., 2011). It is possible that individuals who score highly on OBMT and/or paranormal beliefs subscribe to larger delusional systems (Houran, Irwin, \& Lange, 2001) that make it more likely that they will adopt conspiracy theories. Conversely, and as argued by Swami et al. (2011), it is possible that conspiracy theories fill a need for control that individuals who score highly on paranormal beliefs or OBMT might seek.

Our results also showed that Ideas of Reference (IOR) emerged as a significant, albeit relatively weak, predictor of conspiracist

Table 4

Regression coefficients for the regression predicting conspiracist ideation with SPQ subscales entered as predictors.

\begin{tabular}{|c|c|c|c|c|c|c|c|}
\hline & $B$ & $S E$ & $\beta$ & $t$ & $p$ & Tolerance & VIF \\
\hline Ideas of Reference & .09 & .04 & .15 & 2.03 & .043 & .68 & 1.63 \\
\hline Paranoid & -.06 & .04 & -.10 & -1.77 & .077 & .63 & 1.58 \\
\hline Odd Beliefs/Magical Thinking & .21 & .05 & .24 & 4.37 & $<.001$ & .66 & 1.51 \\
\hline Unusual Perceptual Experiences & .08 & .05 & .10 & 1.46 & .14 & .68 & 1.47 \\
\hline Odd/Eccentric Behaviour & -.07 & .04 & -.10 & -1.67 & .097 & .63 & 1.60 \\
\hline No Close Friends & -.01 & .05 & -.01 & -0.16 & .872 & .70 & 1.44 \\
\hline Odd Speech & -.07 & .04 & -.11 & -1.60 & .110 & .75 & 1.31 \\
\hline Constricted Affect & .03 & .06 & .04 & 0.57 & .571 & .68 & 1.65 \\
\hline Suspiciousness & .08 & .05 & .11 & 1.52 & .129 & .60 & 1.74 \\
\hline
\end{tabular}


ideation. In general, this finding is consistent with previous work reporting significant associations between conspiracist ideation and paranoia (Darwin et al., 2011; Grzesiak-Feldman \& Ejsmont, 2008). Even so, our finding is important because Paranoid Ideation/Suspiciousness did not significantly predict conspiracist ideation in the present sample. That is, it seems that it is the specific concept of IOR, rather than suspiciousness of others, that may build up into a complex conspiracy theory related to the self. Given the finding that conspiracy theories are monological (Goertzel, 1994; Swami et al., 2010), it is plausible that those theories in relation to the self-assist in the assimilation of conspiracy theories related to much larger events.

We acknowledge a number of limitations with our study. First, because we did not include measures other than the BCTI and SPQ, we are unable to examine any possible measurement overlap with constructs omitted from the present work. For example, in future work, it would be useful to concurrently examine the predictive power of variables such as the OBMT and paranormal beliefs in relation to conspiracist ideation. Second, although the reliance on an online recruitment strategy ensured a relatively large sample, our participants are unlikely to be representative of any one nation or community. Finally, although our interpretation of our data is consistent with current theorising (Swami \& Furnham, 2014), causal inferences should be treated with caution because of the crosssectional nature of our data.

Overall, the present results extend earlier work in implicating OBMT and, to a lesser extent IOR, as the primary factors associated with conspiracist ideation. These results may prove useful for scholars seeking ways to reduce the influence of conspiracy theories. For example, Swami et al. (2013) have suggested that promoting analytic over intuitive thinking may be a useful means of attenuating the impact of conspiracy theories. Certainly, the present results suggest that that may be a line of research worth pursuing. More broadly, it would be useful to examine the efficacy of intervention trials aimed at treating prodromal syndromes in relation to reducing belief in conspiracy theories.

\section{References}

Axelrod, S. R., Grilo, C. M., Sanislow, C., \& McGlashan, T. H. (2001). Schizotypal Personality Questionnaire-Brief: Factor structure and convergent validity in inpatient adolescents. Journal of Personality, 15, 168-179.

Brotherton, R., French, C. C., \& Pickering, A. D. (2013). Measuring belief in conspiracy theories: The Generic Conspiracist Beliefs Scale. Frontiers in Psychology, 4, 279. http://dx.doi.org/10.3389/fpsyg.2013.00279.
Bruder, M., Haffke, P., Neave, N., Nouripanah, N., \& Imhoff, R. (2013). Measuring individual differences in generic beliefs in conspiracy theories across cultures: Conspiracy Mentality Questionnaire. Frontiers in Psychology, 4, 225.

Claridge, G. (1997). Theoretical background and issues. In G. Claridge (Ed.), Schizotypy: Implications for illness and health (pp. 3-18). Oxford: Oxford University Press.

Compton, M. T., Goulding, S. M., Bakeman, R., \& McClure-Tone, E. B. (2009). Confirmation of a four-factor structure of the Schizotypal Personality Questionnaire among undergraduate students. Schizophrenia Research, 111, 46-52.

Darwin, H., Neave, N., \& Holmes, J. (2011). Belief in conspiracy theories: The role of paranormal belief, paranoid ideation and schizotypy. Personality and Individual Differences, 50, 1289-1293.

Genovese, J. E. C. (2005). Paranormal beliefs, schizotypy, and thinking styles among teachers and future teachers. Personality and Individual Differences, 39, 93-102.

Goertzel, T. (1994). Belief in conspiracy theories. Political Psychology, 15, $731-742$.

Grzesiak-Feldman, M., \& Ejsmont, A. (2008). Paranoia and conspiracy thinking of Jews, Arabs, Germans, and Russians in a Polish sample. Psychological Reports, $102,884-886$.

Hergovich, A., Schott, R., \& Arendasy, M. (2008). On the relationship between paranormal belief and schizotypy among adolescents. Personality and Individual Differences, 45, 119-125.

Houran, J., Irwin, H. J., \& Lange, R. (2001). Clinical relevance of the two-factor Rasch version of the Revised Paranormal Belief Scale. Personality and Individual Differences, 31, 371-382.

Mason, O., Claridge, G., \& Jackson, M. (1995). New scales for the assessment of schizotypy. Personality and Individual Differences, 1, 7-13.

Raine, A. (1991). The SPQ: A scale for the assessment of schizotypal personality based on DSM-III-R criteria. Schizophrenia Bulletin, 17, 555-564.

Stefanis, N. C., Smyrnis, N., Avramopoulos, D., Evdokimidis, I., Ntzoufras, I., \& Stefanis, C. N. (2004). Factorial composition of self-rated schizotypal traits among young males undergoing military training. Schizophrenia Bulletin, 30, 335-350.

Stieger, S., Gumhalter, N., Tran, U. S., Voracek, M., \& Swami, V. (2013). Girl in the cellar: A repeated cross-sectional investigation of belief in conspiracy theories about the kidnapping of Natascha Kampusch. Frontiers in Psychology, 4, 297.

Swami, V., Chamorro-Premuzic, T., \& Furnham, A. (2010). Unanswered questions: A preliminary investigation of personality and individual difference predictors of 9/11 conspiracist beliefs. Applied Cognitive Psychology, 24, 749-761.

Swami, V., \& Coles, R. (2010). The truth is out there: Belief in conspiracy theories. The Psychologist, 23, 560-563.

Swami, V., Coles, R., Stieger, S., Pietschnig, J., Furnham, A., Rehim, S., et al. (2011). Conspiracist ideation in Britain and Austria: Evidence of a monological belief system and associations between individual psychological differences and realworld and fictitious conspiracy theories. British Journal of Psychology, 102, 443-463.

Swami, V., \& Furnham, A. (2014). Political paranoia and conspiracy theories. In J.-P. Prooijen \& P. A. M. van Lange (Eds.), Power politics, and paranoia: Why people are suspicious of their leaders (pp. 218-236). Cambridge: Cambridge University Press.

Swami, V., Pietschnig, J., Tran, U. S., Nader, I. W., Stieger, S., \& Voracek, M. (2013). Lunar lies: The impact of informational bias and individual differences in shaping conspiracist beliefs about the moon landings. Applied Cognitive Psychology, 27, 71-80. 